The

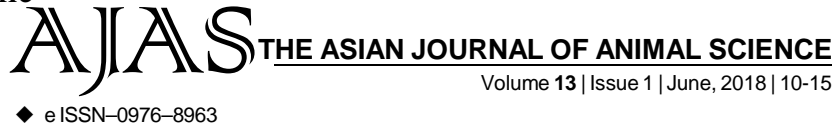

DOI : 10.15740/HAS/TAJAS/13.1/10-15

\title{
Correlation studies on socio-economic status and adoption of recommended practices adopted by goat owners under MAVIM in Akola district
}

Jyoti Y. Mote, K.U. Bidwe, R.R. Shelke and S.D.Chavan

Author for Corresponding -

R. R. Shelke

Department of Animal

Husbandry and Dairy Science,

Dr. Panjabrao Deshmukh Krishi

Vidyapeeth, Akola (M.S.) India

See end of the article for

Coopted authors'
ABSTRACT...... The present investigation on correlation studies on socio-economic status and adoption of recommended practices adopted by goat owners under MAVIM in Akola district district, Department of Animal Husbandry and Dairy Science, Dr. PDKV, Akola during the year 2016-2017. The data of 125 goat keepers belonging to SHG's under MAVIM were collected by personally interviewing with the help of pretested structure. The information about selected characteristics of goat keeper's viz., age, education, family size, family type, flock size, occupation and annual income, sources of information, infrastructural facilities, and sources of motivation, knowledge and adoption was summarized for drawing the conclusion. Finally revealed that majority of the goat keepers were young $(49.60 \%)$ and middle age (48\%) groups. Over one third of those were high schooled, notably cent per cent goat keepers belonged to medium size family that too majority lives in joint family (52\%). Majority of the goat keepers had medium flock size ( 2 to 4 goats) however, goat keeping as major occupation with annual income between Rs. 27,000 to 54,000/-. The important constraints reported by goat owners were non-availability of pure breeding buck, lack of knowledge about breeding practices, housing requirement, non-availability of grazing area. To overcome the constraints it is proposed to train the goat owners of SHG to develop pasture land at Gram Panchayat level for economic feeding of goats and providing loan facilities to goat owners for purchasing foods and fodders, construction of sheds.

KEY WORDS...... Mahilla Arthik Vikas Mahamandal (MAVIM), Shelf-help group (SHG), Goat, Recommended management practices, Adopted practices

HOW TO CITE THIS ARTICLE - Mote, Jyoti Y., Bidwe, K.U., Shelke, R.R. and Chavan, S.D. (2018). Correlation studies on socio-economic status and adoption of recommended practices adopted by goat owners under MAVIM in Akola district. Asian J. Animal Sci., 13(1): 10-15. DOI : 10.15740/HAS/ AJAS/13.1/10-15. Copyright@2018:HindAgri-Horticultural Society.

ARTICLE CHRONICLE - Received : 28.04.2018; Revised : 12.05.2018; Accepted : 23.05.2018 